\title{
PESQUISA-FORMAÇÃO: DIÁRIOS REFLEXIVOS SOBRE OS CUIDADOS COM PROFESSORAS DA EDUCAÇÃO INFANTIL
}

\author{
RESEARCH-TRAINING: REFLECTIVE DIARIES ON THE CARE WITH TEACHERS \\ OF CHILD EDUCATION
}

Clara Maria Miranda de Sousa

Mestra, Universidade de Pernambuco - UPE Petrolina - PE- Brasil

claradassis@gmail.com

Marcelo Silva de Souza Ribeiro

Doutor, Universidade Federal Vale do São Francisco - UNIVASF Petrolina - PE- Brasil mribeiro27@gmail.com

Resumo: O artigo analisa diários reflexivos de professoras da Educação Infantil, compreendendo as formas de vivenciar o cuidado em suas práticas pedagógicas a partir do processo formativo vivenciado. Baseia-se na compreensão de cuidado fundamentada em Heidegger (2005) e Boff (1999), além de articular diálogos sobre formação, saberes docentes e reflexão, conduzidos por Gadamer (2002), Josso (2007) e Freire (2015). A abordagem metodológica foi a pesquisaformação de cunho fenomenológico hermenêutico "heideggeriano". Esta foi realizada em escola da rede pública municipal de Juazeiro - BA, envolvendo treze profissionais. Como dispositivos de colheita de informações foram utilizados: diário de observação, diários reflexivos escritos pelos participantes, roteiros dos encontros formativos e os processos avaliativos. Para este artigo, debruçamo-nos na análise dos diários reflexivos de dois encontros (quarto e quinto encontro) do total de cinco realizados. As análises dos diários foram guiadas pela Analítica do Sentido de Critelli (1996), baseada na perspectiva hermenêutica de Heidegger. As unidades de sentido foram descritas como: a identidade docente e o cuidar, a reflexão da prática docente que contribui para melhor cuidar e formação no sentido de cuidar das professoras da Educação Infantil (EI). A vivência da pesquisa-formação em cuidado, com essas educadoras, mostrou-se um lugar de convivência harmoniosa, de interação, de reflexão da prática, de abertura a si e ao outro, de maneira a favorecer ainda mais a qualidade nas ações educativas, levando a beneficiar toda comunidade escolar.

Palavras-chave: cuidado; educação infantil; pesquisa-formação; professoras.

Abstract: The article analyzes reflexive diaries of teachers of Early Childhood Education, understanding the ways of experiencing care in their pedagogical practices from the formative process experienced. It is based on the understanding of care from Heidegger (2005) and Boff (1999); in addition to articulating dialogues on training, teacher knowledge and reflection conducted by of Gadamer (2002), Josso (2007) and Freire (2015). The methodological approach was the research-formation of the phenomenological hermeneutic "Heideggerian". This was done in a school of the municipal public network of Juazeiro - BA, a total of thirteen professionals. As information gathering devices were used: observation diary, reflective diaries written by the participants, itineraries of the formative meetings and the evaluation processes. For this article, we focus on the analysis of the reflective diaries of two meetings (fourth and fifth meeting) of the total of five meetings. The analyses of the diaries were guided by Critique's Sense Analytic (1996), based on Heidegger's hermeneutic perspective. The units of meaning were described as: teacher identity and care, reflection of teaching practice that contributes to better care and training in the sense of caring for child education (EI) teachers. The experience of research-training in caring, with these teachers has proved to be a place of harmonious coexistence, interaction, reflection on practice, openness to oneself and to others in order to further promote quality in educational actions, leading to benefit to the entire school community.

Keywords: caution; child education; research-training; teachers.

Para citar - (ABNT NBR 6023:2018)

SOUSA, Clara Maria Miranda de; RIBEIRO, Marcelo Silva de Souza. Pesquisa-formação: diários reflexivos sobre os cuidados com professoras da educação infantil. Eccos - Revista Científica, São Paulo, n. 57, p. 1-18, e13682, abr./jun. 2021. Disponível em: https://doi.org/10.5585/eccos.n57.13682. 


\section{Introdução}

As pesquisas sobre formação docente e a qualidade da prática que se traduza em benefícios do desenvolvimento infantil são deveras consolidadas. Contudo, o cenário em torno da profissão docente vem nos revelando a exposição, vivenciada por esses profissionais, no que tangem aos aspectos estressores, conflituosos e permanentemente exigentes. Sem dúvidas, muitos fatores afetam os profissionais dessa área, provocando o sentimento de falta de apoio com a precarização da carreira, com excesso de trabalho extraclasse, baixa remuneração e a falta de recursos para desenvolvimento de melhores práticas (FERREIRA, 2016; MORAIS; LEÃO, 2017).

Como cada área educacional emana suas especificidades, o foco será a partir da realidade que envolve as professoras da Educação Infantil (EI) que atuam em etapa considerada crucial, inclusive nas demais fases da educação básica. Utilizamos do termo professoras pela EI por se tratar de uma área com predominância feminina. Assim, essas docentes têm, sob sua responsabilidade, a facilitação do processo saudável das crianças e a socialização das mesmas na perspectiva da coletividade. Para muitas crianças, o contexto dessa etapa de ensino é um dos primeiros vínculos institucionais e que tem, como tarefa, o exercício de elaboração cidadã, levando cada criança a ser sujeito de direito.

Sabe-se que a EI atende as especificidades do público de crianças entre 0 a 5 anos, no aspecto do cuidar e educar intimamente envolvidos. Tais ações, por sua vez, permeiam as intenções das práticas pedagógicas, demandando da professora uma atenção peculiar de modo a proporcionar um processo de desenvolvimento favorável à criança. Por sua vez, assim como é tratada em vários documentos, a questão do direito das crianças aprenderem, é preciso que elas tenham docentes motivadas e, consequentemente, cuidadas para melhor cuidar dos outros.

Desse modo, o professor atua em uma profissão que agrega níveis de complexidade. Aqueles que se dedicam a tal etapa de ensino aprofundam ainda mais, já que as mudanças entre uma idade e outra acontece de modo rápido, precisando constantemente intervir em prol do bom desenvolvimento. Mediante a necessidade da professora de EI integrar as dimensões do cuidar e do educar e, para tanto, investir em seu processo formativo de autocuidado, podemos levantar os seguintes questionamentos: Quem cuida dessa professora que também cuida da criança? A formação vivida por ela promove cuidado para com as docentes?

O escrito em tela parte de uma investigação maior intitulada "Cuidado em Educação: os sentidos da experiência no contexto de Pesquisa-Formação de professoras da Educação Infantil”, na qual foi desenvolvido um processo formativo em uma escola pública do município 
de Juazeiro - BA. Assim, faremos um recorte de modo a desvelar, por meio de um dos instrumentos, nesse caso, os diários reflexivos e seus processos elaborativos de cuidado.

O objetivo deste artigo, portanto, foi analisar os diários reflexivos de professoras da EI, compreendendo as formas de vivenciar o cuidado em suas práticas pedagógicas a partir do processo formativo vivenciado. A abordagem metodológica é de caráter qualitativo e, no intuito de vivenciar o processo formativo em cuidado, estabelecemos a articulação entre a pesquisaformação e a fenomenologia hermenêutica "heideggeriana", chamada, por nós, de pesquisaformação de cunho fenomenológico hermenêutico "heideggeriano". Essa metodologia vem nos revelar que cada ser compreende a si mesmo e as suas ações no fazer da experiência; deixa de lado o olhar de hipóteses para permitir que, na formação e junto com os demais, possibilite transformações de si e, consequentemente, da realidade em que se está envolvida (JOSSO, 2007; FREIRE, 2015; HEIDEGGER, 2005).

Apoiamo-nos teoricamente em dois autores para tratar de cuidado. O primeiro, considerado o filósofo do cuidado, Martin Heidegger (2005), e o segundo, um dos autores que muito tem discutido o viés do cuidado cosmológico, Leonardo Boff (1999). Para Heidegger (2005), o ser enquanto presença no mundo é cuidado, em que cada pessoa se revela nas suas ações em cuidar. Boff (1999) baseia-se nas ideias de Heidegger, mostra que, sem o cuidado, no humano não existiria cuidar, pois prescinde atenção do se preocupar, do zelar e do ter compaixão para (tem?) si mesmo, com o outro e com o mundo.

Além disso, outros autores contribuíram para a compreensão do fenômeno investigado no estar e fazer a formação com professoras da EI. Ao tratar de pesquisa-formação, aportamonos teoricamente em Josso (2007), Gadamer (2002) e Longarezi e Silva (2008). Como indicações sobre identidade docente, referenciamo-nos em Pimenta (1999), Cunha (2000) e Nóvoa (1992). Sobre o docente que reflete sua própria prática, fundamentamo-nos em Perrenoud (1999) e Freire (2015; 2001). Acerca da escrita reflexiva, baseamo-nos em Zabalza (2004). Quanto às relações grupais, consideramos relevante trazer Rogers (2002) e, finalmente, sobre o cuidado no viés interdisciplinar, trouxemos Fazenda e Pessoa (2013).

O que ora trataremos, parte do "chão" da formação em cuidado promovida junto às professoras da EI, participantes de nosso estudo. Enquanto pesquisadores, gestamos uma formação junto às participantes, engendrando a potência do grupo, que tracejou o modo e o guia das reflexões sobre a prática em cuidar. 


\section{A formação de professoras da educação infantil que emana cuidado}

Iremos situar a formação enquanto fazer da experiência, como outrora afirma Gadamer (2002), ao dar sentido ao termo bildung enquanto estratégia que se lança a cada ser no aspecto de se formar, deformar-se e se transformar na constante retroalimentação experiencial, posto que o humano nunca está pronto e que o inacabamento é próprio de sua condição (FREIRE, 2015).

A formação envolvida de cuidado possibilita que cada professor, no fazer da sua prática, analise-se, interprete-se, sinta-se e se permita escutar e ser escutado. No cotidiano experiencial, ele vivencia angústias, anseios, fraquezas e fortalezas que, por muitos motivos, não se propicia vivenciar os encontros, seja para consigo ou para com os outros (SOUSA; RIBEIRO, 2018).

Ao longo do fazer experiencial, junto com professoras da EI, percebeu-se que a relação entre quem se é enquanto pessoa aproxima-se do ser profissional que vai se transformando pelo tempo, construindo seu ser. Daí é possível apreender que, ao ser profissional, a professora da EI está envolvida e implicada na história e no desenvolvimento de cada criança, fazendo, de sua prática, um momento de constante escolha, de modo a favorecer as subjetividades de todos. O tempo todo, essa pessoa é convocada a fazer escolhas, em especial no que tangem às relações, já que a proximidade com os escolares é bem mais envolvida do que em outras etapas da educação básica.

Na experiência formativa descrita neste artigo, o eixo central para discussão foi o sentido de cuidado em suas várias dimensões: autocuidado, cuidado com o outro, com o mundo e com a prática pedagógica. Foram vivenciados cinco encontros com treze professoras da EI de uma escola da rede municipal de Juazeiro-BA, em horário de serviço e organizados os momentos pelo próprio grupo, no que tange ao espaço e ao tempo. A facilitação foi realizada por dois pesquisadores, que anteriormente se prepararam para desenvolver essa pesquisa-formação, a partir da própria autocompreensão e aprofundando teórico acerca de cuidado em educação.

Em cada encontro, as professoras eram estimuladas a escreverem suas experiências sobre cuidado em um diário reflexivo. Eram feitas as leituras coletivas e o grupo contribuía para a reflexão, deixando vir à tona angústias, esperanças e possibilidades de retomadas. Além dos diários reflexivos, os pesquisadores discutiram as ideias de teóricos como Heidegger (2005), Boff (1999), Freire (2015) e Rogers (2002), como contribuição no fazer docente da EI no modo de cuidar.

Nesse sentido, a formação enquanto espaço de cuidado, vivencia a dinâmica de existir sendo ser-aí e sendo ser-no-mundo com os outros; compreende a realidade, preocupando-se e 
se ocupando com o cuidar de si, do outro e do mundo, utilizando-se dos utensílios a sua disposição para melhor favorecer essa ação.

O modo-de-estar no mundo dessas profissionais perpassa pelas práticas junto à infância, esforçando-se para que a linguagem, os afetos e os diversos momentos sejam espaços de aprendizados férteis para protagonizar a ética do cuidado, que leva cada ser a não somente pensar em si, mas na coletividade, respeitando os tempos e os jeitos de ser e estar no mundo. Ao cuidar do professor, tem-se a possibilidade de multiplicar o cuidado, já que cada um repercutirá tais saberes na vida (BOFF, 1999).

Para tanto, este artigo foi organizando em três seções. Na primeira seção apresentam-se os procedimentos realizados pela pesquisa-formação em cuidado. Após, será exposta a análise dos resultados e discussões quanto à escrita dos diários reflexivos das docentes da EI, participantes da pesquisa-formação, assim como o aporte teórico que contribui para a compreensão do fenômeno investigado. Por fim, a terceira seção constitui-se das considerações finais.

\section{Procedimentos metodológicos}

Este estudo é oriundo de uma investigação qualitativa, sendo mais especificamente pesquisa-formação de cunho fenomenológico hermenêutico "heideggeriano", tendo em vista a compreensão dos sentidos do cuidado de professoras da EI de uma escola municipal de Juazeiro-BA. A perspectiva dessa pesquisa foi inicialmente pensada na formação de professores, mas podendo ser experimentada em outros grupos. Esse jeito de pesquisar valoriza a participação ativa de todas as pessoas do grupo, uma vez que juntos podem ensinar e aprender algo (JOSSO, 2007; FREIRE, 2015; HEIDEGGER, 2005).

O campo de estudo foi uma escola de Educação Infantil, localizada em um bairro periférico da cidade de Juazeiro-BA, pertencente à Rede Pública Municipal. A escola funciona nos períodos matutino e vespertino, atendendo cerca de 250 crianças com idade entre 0 a 5 anos, não somente residentes no bairro em que está localizada, mas também na circunvizinhança. Possui uma equipe administrativa composta por gestora, secretária, duas cozinheiras, duas assistentes de serviços gerais e dois porteiros; além da equipe pedagógica com uma coordenadora, onze professoras e cinco auxiliares de sala. $\mathrm{O}$ prédio tem um estilo padrão do Programa Nacional de Reestruturação e Aquisição de Equipamentos para a Rede Escolar Pública de Educação Infantil (Proinfância), instituído pela Resolução no 6, de 24 de abril de 
2007, tendo sido financiado pelo governo federal por meio de parceria com o município (BRASIL, 2007).

O grupo em que a pesquisa-formação foi realizada era composto por 11 professoras da EI (quatro delas são do quadro efetivo da secretaria de educação municipal e as demais são contratadas), além da gestora e da coordenadora da escola, que solicitaram participar e foram aceitas pelo grupo de professoras. Foi sugerido que cada uma escolhesse o nome que gostaria de ser identificada nos textos escritos e que fosse referente ao seu modo de cuidar. As participantes escolheram como nomes: Afeto, Alegria, Amor, Carinho, Criatividade, Determinada, Fé, Fortalecida, Guerreira, Humilde, Paciência, Simplicidade e Sorriso.

Os encontros foram realizados em uma sala da escola reservada para reuniões de professores e o tempo destinado foi em torno de uma hora e meia a duas horas, o qual foi organizado pelo próprio grupo, considerando seus horários de serviço e a periodicidade quinzenal. Nesse espaço de tempo, as turmas de EI realizavam atividades coletivas com as auxiliares de sala, com o intuito de garantir os dias letivos e a rotina escolar.

Como dispositivos de colheita de informações foram utilizados: 1) diário de observação direta no campo de pesquisa, para registrar elementos significativos; 2) diários reflexivos escritos pelos participantes, permitindo trazer a produção de sentidos das experiências vividas a partir do cuidado, sendo escritos quatro diários por cada participante e solicitados conforme as temáticas trabalhadas nos encontros; 3) roteiros dos encontros formativos e suas devidas execuções; e 4) os processos avaliativos foram desenvolvidos ao final de cada encontro, com o intuito de perceber o andamento das ações, acompanhando pontos significativos e possibilitando melhoria ao longo do processo. Para o propósito deste artigo, foram as informações concernentes aos diários reflexivos que serviram de base para as análises.

O projeto, inicialmente, foi submetido ao Comitê de Ética, aprovado e registrado com o CAAE de $n^{\circ}$ 68415917.9.0000.5207. Tivemos o consentimento da direção da escola, registrado na Carta de Anuência da responsável pela instituição. As participantes da pesquisa foram informadas dos objetivos e procedimentos utilizados; assinaram o Termo de Consentimento Livre e Esclarecido (TCLE).

Para este artigo, como já assinalado, debruçamo-nos na análise dos diários reflexivos, relativos a dois encontros (quarto e quinto), no total de cinco. As temáticas referentes aos dois encontros supracitados foram: A professoraleducadora como cuidadora: o envolvimento do cuidar nas práticas educativas e O lugar do cuidado em educação: refletindo os processos transformadores na formação. 
No primeiro dia de encontro, foi entregue, pela equipe de pesquisa, um diário explicando que tal instrumento seria utilizado como uma proposta de reflexão sobre si e suas práticas de cuidado. Assim, em todos os encontros, era sinalizada uma consigna para que as participantes pudessem escrever os sentidos de suas vivências acerca do cuidado que se revelasse em suas práticas pedagógicas. No quarto encontro, a consigna para escrita do diário reflexivo foi "Como percebo o cuidado em minha prática pedagógica?”. E, no quinto encontro, “Avaliação da pesquisa-formação referente a cuidado". Em cada encontro elas traziam os diários reflexivos e faziam as leituras como modo disparador da discussão.

Zabalza (2004) mostra que o professor, ao escrever acerca de si e de sua prática, acumula informações e se implica no processo percebendo sua própria evolução. Os diários reflexivos sobre cuidado das docentes investigadas se mostraram instrumentos de autodesenvolvimento e de melhoria pessoal e profissional.

As análises dos diários foram guiadas conforme a Analítica do Sentido (CRITELLI, 1996), baseando-se na perspectiva hermenêutica de Heidegger. Com todo o material colhido e a situação hermenêutica estabelecida, buscamos chegar às temáticas de sentido junto ao grupo, já que foi agendado um momento para as análises, resultados e discussões, afinal era uma proposta de investigação assumidamente participativa (uma pesquisa-formação). A partir de várias leituras do material coletado e as temáticas de sentido que se clarificaram, foram reunidos os temas que se relacionavam e desvelado o fenômeno investigado, ampliando, assim, a compreensão do mundo vivido das professoras quanto ao cuidado (CRITELLI, 1996).

O método de Analítica do Sentido, desenvolvida na via da fenomenologia hermenêutica "heideggeriana" vem, pois, refletir o modo do humano se perceber como ser-no-mundo, emergindo os significados, compreendendo o sentido do fenômeno e ocorrendo na cotidianidade do ser. Critelli (1996) ainda mostra que a compreensão do ser vive um eterno movimento do vir-a-ser, estando em constante mudança, mas abrindo o espaço para a significação das escolhas feitas mediante a existência.

\section{A escrita reveladora das experiências de cuidado na educação infantil}

Nesta parte do artigo, dedicamos aos resultados e às discussões, a partir da análise de alguns trechos dos diários reflexivos escritos pelas professoras de EI, participantes da pesquisaformação, acerca dos sentidos de cuidado em suas práticas pedagógicas e pela participação nesse processo formativo.

$\mathrm{Na}$ escrita de seus diários reflexivos, elas tratam de questões bem pessoais e das relações de trabalho, sejam com as colegas, como com as crianças que fazem parte de seus cotidianos. 
Para Zabalza (2004), o professor que escreve sobre sua prática, aprende com a sua narração, construindo e reconstruindo o seu fazer profissional. Elas vivenciaram a experiência de confrontarem a realidade, os seus sentidos e, consequentemente, sua maneira de estar na EI, construindo a si mesmo pelo viés da tomada de consciência em cuidar.

As participantes tinham, em sua maioria, idades entre 30 a 39 anos (53\% do total do grupo) e as demais entre 20 a 29 anos (correspondendo a 15\%). Apenas 7\% delas realizaram sua formação acadêmica em outras áreas que não fosse o curso de Pedagogia.

Quanto ao tempo de experiência profissional na área, pode-se observar que o maior quantitativo foi entre 1 a 5 anos (38\% do grupo), enquanto que o menor valor foi entre 10 a 15 anos (15\% do grupo). O tempo relacionado à experiência profissional vem a ser um dado relevante à medida que identifica o grupo de maneira diversificada, pois cada uma porta sua história profissional, formação acadêmica singular e com práticas de ensino que revelam um jeito de ser próprio. Nessa démarche, Rogers (2002) indica-nos que estamos em contínuo processo de transformação e construção, nunca somos totalmente, mas vamos sendo. Freire (2001), por sua vez, mostra que estamos em mudança, que o ato de ensinar/aprender não é algo determinado a ser vivenciado da mesma forma com todas as pessoas. O patrono da educação brasileira ainda fala da "docência decente", que deve envolver, inclusive, a afetividade, a relação, a ética e a estética.

Apresentamos, assim, a partir de três unidades organizadas por meio da Analítica do Sentido (CRITELLI, 1996), os sentidos quanto ao cuidado na prática pedagógica e as contribuições da pesquisa-formação. Desse modo, as unidades são descritas como: a identidade docente e o cuidar, a reflexão da prática docente que contribui para melhor cuidar e formação no sentido de cuidar das professoras da EI.

\section{A identidade docente e o cuidar}

$\mathrm{Na}$ EI, temos como cenário, em sua maioria, mulheres que constroem seus percursos profissionais e pessoais de modo singular. Pode-se até considerar que o seu fazer profissional perpassa o seu estar envolvido com o doméstico (CUNHA, 2000). Sendo assim, a sua identidade docente não pode ser vista desvinculada do seu ser pessoa. A professora, dessa etapa, envolve a sua prática de cuidado pelo seu processo de identidade.

Heidegger (2005), ao tratar da questão do ser, expõe que pelos modos de demonstração em estar com o outro, revela-se a si mesmo. Ainda explana que ser está na realidade de se colocar enquanto presença, constantemente nos questionando- e sendo questionado. Trazendo 
essas contribuições para pensar a perspectiva de identidade docente da professora da EI, refletimos que cada ação propagada por meio da prática é um lugar de revelação do ser, constituindo-se e buscando possibilidades de como melhor estar no seu fazer cotidiano.

A professora Criatividade escreve em seu diário reflexivo:

Amo minha profissão, pois através dela tenho a oportunidade e função de cuidar de muitas vidas. Tenho dificuldade de construir coisas coletivamente, pois gosto que fique do meu jeito. No entanto, tenho tentado me policiar e trabalhar com essa minha dificuldade e já melhorei bastante.

Segundo Boff (1999), o cuidado surge quando se dá importância ao sentido que o outro tem para com a própria existência. A professora Criatividade sinaliza que gosta da profissão, que se dedica a contribuir para o desenvolvimento de cada criança percebe suas fragilidades quanto ao fazer coletivo, mas que tem a coragem de se lançar para mudar. Esse processo não se dá de uma hora para outra, pois cada ser é uma pessoa e a professora da EI precisa de apoio em suas várias demandas, sentindo ânimo em se envolver e estar com as outras colegas, com a possibilidade de formar o seu jeito de participar do coletivo.

Corroboramos com Perrenoud (1999), ao tratar da prática reflexiva profissional como participação coletiva, em que um profissional apoia o outro. Para o autor, a prática poderá até ser solitária, mas sempre perpassará pelo outro que está externo, seja por conversas informais ou contribuições formativas.

A professora Carinho contribui nessa reflexão escrevendo:

[...] O meu trabalho me realiza, foi a partir dele que percebi que posso ser bem útil, que posso somar em uma equipe, que posso contribuir realmente para uma melhoria. E como faço isso? Dando o meu melhor, fazendo o melhor que posso não para que o outro reconheça, mas para que eu realmente me sinta bem e tenha aquela sensação boa de dever cumprido, de que meu trabalho é importante e significativo.

Ao refletir sobre esse escrito da professora Carinho, interacionamos com a ideia de Pimenta (1999) acerca da construção da identidade docente, afirmando que a absorção dos saberes propicia a autonomia, buscando sempre aperfeiçoar as suas práticas e tomando novas decisões no intuito de ser agente ativo do processo. A professora Carinho pontua que os resultados contribuem para que esteja buscando outros modo-de-ser-cuidado no espaço profissional, permitindo-se perceber o valor intrínseco de ser professora da EI.

A professora Carinho demonstra que sua identidade docente se constitui pelo sentimento de inacabamento, ou seja, sempre em busca de aperfeiçoar a si e a sua prática. Segundo Freire (2015), o bom educador tem consciência de seu inacabamento, experiência essa que envolve toda a nossa vida, já que nunca estaremos concluídos e prontos. A professora da EI que 
compreende o seu inacabamento, terá a possibilidade de estabelecer meios de busca para formar a si mesmo,

A docente Determinada sinaliza que "não tenho como desenvolver um trabalho sem se envolver com as práticas educativas. Os alunos são sensíveis a estímulos, requerendo empolgação do professor durante a proposição das atividades”. Segundo Heidegger (2005), o ser está sempre envolvido com o outro. Isso quer dizer que cada criança constitui o fazer docente da professora de EI.

Nas práticas da EI, o cuidado vem primeiro. Segundo Fazenda e Pessoa (2013), tudo envolve o sentimento, o ponto de partida é o que se sente, posteriormente vem a razão. Tal professor, por vários motivos, envolve-se afetivamente com as crianças, mantendo vínculos empáticos, trazendo, à memória, muitos que por ele passou. A docente Amor assim escreve:

\footnotetext{
Durante todo esse meu trajeto como professora educadora, tentei me colocar no lugar do aluno. E até mesmo não observando somente o meu aluno, mas os alunos de um modo geral. Procurando não somente vendo a criança, mas observá-la de maneira integrada em todas as dimensões.
}

De acordo com Boff (1999), ao darmos valor as nossas ações, colocamos nela cuidado. Para isso, a professora de EI se envolve de todas as maneiras com as crianças que estão sob a sua responsabilidade de acompanhar seus desenvolvimentos, lançando-se a compaixão para com os que sofrem e sentindo-se implicado na vida do outro. A sua identidade docente passa também pela coerência de ver o aluno para além de um simples aprendiz, mas vê-lo enquanto pessoa que está construindo a sua humanidade, vinculada ao modo de ser humano do educador.

Nessa prática, pelo grau de envolvimento com cada criança, as professoras observam cada passo e seu jeito de ser docente. Como mostra a escrita de Sorriso, "para cuidar da prática pedagógica precisa gostar do que faz e o que faço é por vocação, responsabilidade e humildade. Tenho consciência que estou trabalhando com vidas em processo de formação. Somos espelhos aos olhos das crianças". A docente Fortalecida também escreve "você tem que procurar se aproximar da criança. E as crianças observam você".

Para Sorriso e Determinada, o estar nesse campo de atuação permeia o autocuidado de se compreender, identificar suas habilidades e desejos. A professora tem que gostar de estar no ambiente junto com os outros, sejam elas crianças, pais e colegas. Caso contrário, desencadearse-á sofrimento a ele e a todos ao seu redor, tornando a escola o lugar do descuido, acarretando malefícios a si mesmo.

Boff (1999) expõe que cuidamos do que amamos e amamos do que cuidamos. A professora Afeto escreve em seu diário: “Amo vivenciar o 'mundinho' das crianças. Gosto do 
que faço, pois para mim é muito prazeroso". Na relação pedagógica, a docente da EI é uma interlocutora de boas novas, assim, a afetividade precisa ser primordialmente vivenciada junto aos alunos. $\mathrm{O}$ afeto também é algo que se aprende e, nesses primeiros anos, é crucial que a criança compreenda a si mesma, o que sente e como ir melhorando por meio do processo interventivo realizado no espaço da escola.

Percebe-se que o cuidado da prática docente das participantes da pesquisa-formação se dá pelas escolhas realizadas profissionalmente, com o desejo de buscar novas maneiras de compreender a realidade; pela formação continuada; por meio dos vínculos junto aos outros e pela consciência da responsabilidade com cada criança da EI. Desse modo, a unidade de sentido, a seguir, complementará tal discussão, ao tratar da reflexão da professora como meio para melhor cuidar no seu fazer docente.

\section{A reflexão da prática docente que contribui para melhor cuidar}

O cuidar envolve refletir sobre o que se é e o que se faz. O diário reflexivo foi um forte instrumento de retomada das práticas e dos momentos destinados a se perceber também enquanto pessoa. Nörnberg (2007), ao tratar sobre o lugar do cuidado na formação de professores, indica que se torna verdadeiro espaço de apresentação de suas percepções, das angústias, ampliando o sentido educativo das ações nos atos de ensinar. A docente Simplicidade assim expõe:

Trabalhar com a educação infantil é encantador, é apaixonante. Contudo, é desafiador e em alguns momentos até frustrante. Pois, há momentos que nos deparamos frente a um enorme abismo entre a teoria e a prática. É como se fossem duas coisas totalmente distintas e todo sentimento de insegurança, de saber fazer, se dissolve como açúcar na água e de repente surge um sentimento de impotência, insegurança e incapacidade.

Simplicidade, ao expor abertamente acerca do problema inicial trazido por ela, que seria a limitação sentida, emerge a reflexão sobre si, sua profissão e a formação adquirida de maneira teórica e prática. Conforme Josso (2007), quando algum participante expõe questões e preocupações ao grupo na pesquisa-formação, revela-se o começo da reflexão do processo formativo, como saída do seu isolamento no desenvolvimento de novas maneiras de resolver as situações inicialmente trazidas.

Para Heidegger (2005) é condição humana ocupar-se desempenhando atividades que indiquem o "Ser" da sua existência. O conflito faz parte, já que envolve refletir, experimentar, em dados momentos desanimar, mas nunca desistir de continuar a tentar. O "Ser" retoma pela 
criatividade e o desejo por cuidar, transformando a desesperança em novidade de ação. Como escreve a professora Determinada:

O cuidado com a minha prática se dá a partir do momento em que busco conhecimentos para melhor desenvolvê-la. Através de capacitações, formações e também pela análise dos resultados que apontam se estou indo no caminho certo com a proposta educacional dos alunos.

O próprio termo cuidado se imbrica de "poder-ser", ela se põe a se autoavaliar e avaliar os alunos cotidianamente, observando o andamento do processo, como também o seu modo de exercer a docência. É necessário que a professora da EI esteja em constante busca de se atualizar, pois nem sempre a formação inicial permite-lhe entender a complexidade que se apresenta no trabalho docente. A formação continuada, exemplificada aqui sobre e com o cuidado, contribuiu para que cada uma se aprofundasse de maneira teórico-prática, construindo novos modos de estar na docência.

A EI exige, da profissional, fundamentos teóricos para compreender que, em cada etapa de ensino, as habilidades podem ser promovidas, respeitando a faixa etária das crianças e trazendo aspectos da própria realidade para levá-las a aprimorarem seus conhecimentos. A professora Paciência compartilha em seu diário reflexivo que

Procuro me divertir com a rotina da sala com coisas novas, como brincadeiras e atividades. Tudo dirigido com um objetivo dentro do planejado, tendo autonomia para agir em todos os momentos. Além de deixar as crianças livres para interagir com segurança.

Complementando, a docente Afeto também escreve: "Gosto de aulas lúdicas, utilizar muitas dinâmicas para que os momentos com as crianças fiquem prazerosos". A professora da EI pode ser vista como aquela que está constantemente pensando na sua prática, planejando alguma atividade para possibilitar que a aprendizagem ocorra em todos os momentos. Importante considerarmos o exíguo tempo reservado para o planejamento, uma vez que o professor vivencia dupla jornada de trabalho e o momento de descanso é comprometido com as ações profissionais desenvolvidas em casa.

As docentes Paciência e Afeto sinalizam uma rotina com novidades, propiciando ambiente favorável para o desenvolvimento da aprendizagem de cada criança. Freire (2015) mostra que a autonomia que o professor constrói junto com o aluno, leva-o a vivenciar a liberdade em pensar e criar novos modos de conhecer. A docente da EI, enquanto mediadora da aprendizagem, é uma cuidadora que acompanha o vislumbre da criança ao aprender, propagando práticas que podem se moldar na vivência de cada aluno em seu processo de desenvolvimento. 
Tal etapa, enquanto espaço de cuidado, não somente propicia vivência das suas ações na dimensão de ensinar texturas, cores, movimentos, mas também é lugar de diálogo, em que a professora está aberta para ouvir o que os estudantes têm a dizer, sejam suas intenções como suas vivências. Segundo Fazenda e Pessoa (2013), os educadores não estão preparados para tornar o ambiente educacional o espaço de reflexão sobre a vida. Assim, podemos perceber que a formação é um meio favorável para se construir novos saberes, para refletir sobre a prática e criar interação entre teoria e prática, não as compreendendo de maneira dissociada.

O cuidado na pesquisa-formação se mostrou espaço privilegiado de reflexão, em que houve identificações, novos enfrentamentos ao jeito de ser e fazer, mas especialmente em lugar de aprendizagem. Com isso, a próxima unidade de sentido trará a formação enquanto meio favorável para repensar o cuidado na EI.

\section{Formação no sentido de cuidar das professoras da educação infantil}

A formação é um verdadeiro lançar-se às fronteiras do desconhecido. Não conseguiremos acrescentar algo sem experimentarmos e nos moldarmos cotidianamente. Gadamer (2002) expõe o conceito bildung enquanto formação, na dimensão de potencialização do que se é, ou seja, aquele que busca a formação não sai da mesma forma, ele aprimora as suas habilidades e projeta outros modos de ser. Corroborando com essa ideia, a professora Simplicidade escreve:

\footnotetext{
Os encontros possibilitaram a compreensão da infinitude e diversidade do que seja CUIDAR. Onde nos deleitamos com reflexões teóricas e vivenciamos atitudes cuidadosas de afetos e trocas. Enfim, uma experiência significativa que contribuiu para a harmonia no ambiente escolar e despertou o desejo de cuidar mais de si e dos que estão ao redor.
}

Em seu relato, ela sinaliza para a formação que provocou novos modos de perceber o cuidado e concluiu que cada um tem sua maneira de cuidar. Heidegger (2005) indica que, na busca por entender o ser, cada um é capaz de deixar e fazer ver os sentidos de estar presente no mundo. Dessa forma, tais momentos formativos foram vistos como significativos, contribuindo para que todos fossem beneficiados.

A formação que propicia cuidado para com as professoras da EI, reservando tempo e espaço para que aconteça a imersão reflexiva, torna-se um lugar prazeroso, sem julgamentos e com possibilidade de motivar a quem participar. Para Heidegger (2005), o cuidado está envolvido com o ser e o tempo, pois somente ao humano é possibilitada a inquietude pelo processo de vir-a-ser. A formação, tomada como lugar de cuidado, se expressa como espaço para estabelecer a relação de convivência harmoniosa consigo, com o outro e com o mundo. A 
docente Humilde escreve: "Esse momento fez com que o grupo se aproximasse mais através dos relatos pessoais, onde nos proporcionou a descoberta das ansiedades e fragilidades de cada colega de trabalho".

Ao longo de horas semanais, essas pessoas estão envolvidas na prática sem ao menos conhecer direito com quem trabalham. Pela convivência, segundo Boff (1999) o cuidado se mostra na sensibilidade, sem o estabelecimento da ideia voraz do poder-dominação. Na formação pelo viés do cuidado, todos estão em processo de construção e a experiência contribuirá de algum modo, não somente em suas práticas docentes, mas na vida.

As professoras Criatividade e Amor avaliam o processo da pesquisa-formação em cuidado da seguinte forma:

\begin{abstract}
Estou muito feliz por participar desse projeto de pesquisa em formação de professores, foram momentos significativos, onde pude refletir sobre o ato de cuidar do outro, do meio onde vivo e principalmente comigo mesma, pois se eu não estiver bem, não tenho como cuidar de nada e nem de ninguém. (CRIATIVIDADE)

Com o passar dos dias e tendo que refletir sobre o momento profissional que estava vivendo, percebi que essa situação não estava boa e que tinha que ser tomada com atitude séria e corajosa, pensando no meu bem-estar e nas pessoas que conviviam comigo. [...] Com a formação em cuidado fomos beneficiadas e nossos alunos também. (AMOR)
\end{abstract}

Longarezi e Silva (2008) trazem que a pesquisa-formação deve ter esse olhar apurado para a experiência do docente de modo individual e coletiva, construída em seu cotidiano. As docentes Criatividade e Amor mostram a tomada de consciência vivida por meio da formação em cuidado. Para ambas, o cuidado só será vivenciado de maneira qualitativa com os outros, se primeiro cada uma conseguir se autocuidar.

Cada participante mostrou-se, como diz Heidegger (2005), ser-com-os-outros, ou seja, que não se podia perceber a si mesma de maneira isolada, mas a realidade é vivenciada com um conjunto de demandas a serem transpostas e tendo a disposição para melhorar a si, com o intuito de estar com o outro. Dessa maneira, explana a professora Determinada: "A partir dos encontros, eu pude perceber que eu tinha que mudar em alguns aspectos. [...] Aprendi o cuidado com as colegas de trabalho e ter um olhar especial para cada um dos meus alunos".

A docente Paciência relata que:

Na minha concepção foi um grande momento em poucos dias, experiência rica, um “chá" de realidade que está bem esquecida. Pude conhecer um pouco das colegas, descobrindo fragilidades, medos, determinações, perfeccionismo e insatisfações. Aonde o olhar não fala por si só. 
Nesse escrito, percebe-se que a participante vivenciou essa experiência gerando descobertas que levará para o seu cotidiano. Para Boff (1999), pelo cuidado criamos novos sentidos e inventamos novas coisas. Desse modo, a professora Paciência concebe que os dias formativos foram poucos, mas que cada momento representou uma riqueza em poder estar junto, tratando sobre suas experiências de cuidado na EI e em suas trajetórias, vivenciando a possibilidade de uma formação que saia diferente, com a consciência em contribuir com práticas que levem tanto a elas quanto aos alunos estarem bem.

Ao falar sobre a relação com o grupo, Guerreira diz:

eu pude me sentir mais a vontade com cada uma delas [...] esses encontros me deram a oportunidade de falar e ouvir cada uma. Saímos mais leves, dispostas a mudar em alguns aspectos. [...] Como profissional pude olhar cada aluno com olhar que eles merecem e que esta experiência vai me deixar um legado para toda a vida.

A professora Guerreira, bem como as demais, demonstrou a dimensão de abertura para que fosse capaz de explorar o sentido quanto ao cuidado, dentro e fora de sua profissão docente. O ser tem infinitas possibilidades de construir sua existência, por meio da busca de se compreender junto com outros; a professora Guerreira extraiu habilidades de cuidado quanto à atenção disponibilizada ao outro, contribuindo fortemente em sua prática na EI.

$\mathrm{Na}$ dimensão de temporalidade, Heidegger (2005) mostra que cuidamos dentro de um tempo e espaço no qual somos lançados. A professora Afeto indica, em seu escrito, "o que foi absorvido nos encontros jamais será esquecido". A palavra decorar tem sua significação em guardar na memória do coração. Assim, os vários momentos vivenciados mostraram-se o espaço do sentir, em que cada participante poderia ser verdadeiramente quem era, sem medo de ser julgada, mas que fosse um espaço de construção de ser pessoa. Não somente podemos pensar a docência de maneira isolada, mas envolvida de ricas experiências em outros espaços além da escola. A participante Fé assim escreve "o cuidar está na nossa rotina do dia a dia com família, profissão, amigos, colegas etc.”.

Para Nóvoa (1992), a formação encerra o projeto de ação e se inicia o momento de transformação. Dessa forma, no campo profissional das professoras de EI, a formação pode ser um terreno de cuidado, seja ele pelos espaços de escuta ou de reflexão da prática. A vivência da pesquisa-formação em cuidado se mostrou um lugar de convivência harmoniosa, de interação, de reflexão sobre e com a prática, de abertura a si e ao outro, e de atitudes de construção da existência de maneira a favorecer ainda mais a qualidade nas ações educativas, levando a beneficiar toda a comunidade escolar. 


\section{Considerações}

As participantes da pesquisa, considerando o viés do cuidado, revelaram as suas ações com compromisso nas suas escolhas. Mostraram que se identificam com o que fazem e refletiram acerca das suas práticas, buscando melhorar ainda mais a si mesmas e o seu serprofissional. As docentes, apoiando-se umas às outras, sentiram que o seu fazer cotidiano poderá ser gerenciado de maneira mais tranquila, inclusive propondo novas formas de ação pedagógica. O cuidar se mostra como modo-de-ser, seja estando no espaço educacional ou mesmo na convivência com os familiares.

A pesquisa-formação em cuidado ampliou as possibilidades de escolhas em aperfeiçoarem a si mesmas por intermédio do aparato reflexivo vivenciado pelos encontros. Puderam, desse modo, reconhecerem-se suas vulnerabilidades; desenvolverem o afeto com as colegas, compreendendo-as e respeitando-as nos seus tempos e modos de refletir a prática. $\mathrm{O}$ cuidado integrou todas as participantes, criando novos sentidos de como estar na EI.

Um dos benefícios trazidos por esse tipo de pesquisa é facilitar o processo de tomada de consciência. Isso se dá quando cada participante reflete sobre suas ações, pensamentos, modode-ser, desejando aprimorar ainda mais o seu existir a partir do ser-cuidado. No caso deste estudo, as professoras da EI puderam refletir sobre si e sobre aqueles que estão a elas vinculadas, possibilitando que suas ações fossem redinamizadas, qualificando o fazer docente pelo cuidado.

\section{Referências}

BRASIL. Resolução no6, de 24 de abril de 2007 - Programa Nacional de Reestruturação e Aquisição de Equipamentos para a Rede Escolar Pública de Educação Infantil (Proinfância). Disponível em http://www.fnde.gov.br/fnde/legislacao/ resolucoes. Acesso em: 12 out. 2017.

BOFF, Leonardo. Saber cuidar: ética do humano compaixão pela terra. 7 ed. Petrópolis, RJ: Vozes; 1999.

CRITELLI, Dulce Mára. Analítica do Sentido: uma aproximação de interpretação do real de orientação fenomenológica. São Paulo: EDUC: Brasiliense, 1996.

CUNHA, Maria Isabel da. Ensino como mediação da formação do professor universitário. In: MOROSINI, Marília et al. (org.) Professor do Ensino Superior: identidade, docência e formação. Brasília: INEP, 2000, p. 45-51.

FAZENDA, Ivani Catarina Arantes; PESSOA, Vânia Inês Fontenele (Org.). O cuidado em uma perspectiva interdisciplinar. Curtiba, PR: CRV, 2013. 
FERREIRA, Thayrene Vieira. Saúde do professor: uso de medicamentos por professores da rede estadual de educação de Rio Verde/Goiás. 2016. 140f. Dissertação de Mestrado. Universidade Federal de Goiás, 2016.

FREIRE, Paulo. Pedagogia da autonomia: saberes necessários à prática educativa. 51. ed. São Paulo: Paz e Terra, 2015.

FREIRE, Paulo. Pedagogia do oprimido. 31. ed. Rio de Janeiro: Paz e Terra, 2001.

GADAMER, Hans-Georg. Verdade e método: traços fundamentais de uma hermenêutica filosófica. Petrópolis, RJ: Vozes, 2002.

JOSSO, Marie-Christine. A transformação de si a partir da narração de histórias de vida. Revista Educação, Porto Alegre/RS, ano XXX, n. 3 (63), p. 413-438, set./dez. 2007.

HEIDEGGER, Martin. Ser e Tempo. Parte I. 15 ed. Petrópolis, Rio de Janeiro: Vozes, 2005.

LONGAREZI. Andréa Maturano; SILVA, Jorge Luiz. Interface entre pesquisa e formação de professores: delimitando o conceito de pesquisa-formação. In: VIII CONGRESSO

NACIONAL DE EDUCAÇÃO - EDUCERE: formação de professores, 3., 2008, Curitiba. Anais do VIII Congresso Nacional de Educação - EDUCERE, Curitiba: Champagnat, 2008, p. $4048-4061$.

MORAIS, Silvia Raquel Santos; LEÃO, Gisele Dark Batista. Compreensões de adoecimento psíquico segundo educadora afastada do trabalho em Juazeiro-BA. REVASF, Petrolina-PE, v. 7, n.12, p. 80-99, abril, 2017.

NÖRNBERG, Marta. O lugar do cuidado na formação de professores. Diálogo, n. 11, p. 211234, 2007. Disponível

em:https://biblioteca.unilasalle.edu.br/docs_online/artigos/dialogo/2007_n11/mnornberg.pdf. Acesso em: 10 fev. 2018.

NÓVOA, António. O Espaço Público da Educação: Imagens, Narrativas e Dilemas. In: PROST, Antoine, et al. Espaços da Educação - Tempos de Formação. Lisboa: Fundação Calouste Gulbenkian, 2002.

PERRENOUD, Philippe. Formar professores em contextos sociais em mudança: Prática reflexiva e participação crítica. Revista Brasileira de Educação, 12, 5-21, 1999. Disponível em: https://www.unige.ch/fapse/SSE/teachers/perrenoud/php_main/php_1999/1999_34.html Acesso em: 12 jan. 2019.

PIMENTA, Selma Garrido. (org.) Saberes pedagógicos e atividade docente. São Paulo: Cortez, 1999.

ROGERS, Carl. Grupos de Encontro. 8. Ed. São Paulo: Martins Fontes, 2002.

SOUSA, Clara M. M. de; RIBEIRO, Marcelo S. de S.. Cuidado em educação: os sentidos da experiência no contexto de pesquisa formação com professoras da educação infantil. 2018. 240f. Dissertação (Mestrado em Educação) - Programa de Pós-graduação em Formação de Professores e Práticas Interdisciplinares, Universidade de Pernambuco, Petrolina - PE. 
ZABALZA, Miguel. Diários de aula: um instrumento de pesquisa e desenvolvimento profissional. Tradução Ernani Rosa. Porto Alegre: Artmed, 2004. 